\title{
Expectations and Satisfaction of Physicians with Patient Referral Services in General Hospitals
}

\author{
Hyun Hee Park ${ }^{1}$, Kwang Ok Lee ${ }^{2}$ \\ ${ }^{1}$ Part Manager, Department of Medical Cooperation Center, National Health Insurance Service Ilsan Hospital, \\ South Korea, ${ }^{2}$ Associate Professor, Department of Nursing, Sangmyung University, South Korea
}

\begin{abstract}
This study aimed to suggest some ways to improve the referral center system and to revitalize referral centers by investigating physicians' expectations and satisfaction with referral centers in general hospitals. A cross-sectional study was performed at general hospitals. The participants were 124 private practitioners who referred patients to general hospitals. The data were collected using a questionnaire survey from January 25 to April 25, 2020. The physicians' expectations and satisfaction with the referral center were higher in the cooperating hospital than in the non-cooperating hospital. The average expectation of the participants in a cooperating hospital was higher (4.13 \pm 0.87$)$ than in a non-cooperating hospital (4.0 \pm 0.97$)$. The average satisfaction of the participants in the cooperating hospital was higher (3.72 \pm 1.03$)$ than in the non-cooperating hospital $(3.57 \pm 1.02)$. The rapid booking process and treatment and kindness of staff at the referral center significantly correlated with the participants' satisfaction. This study suggests that the expectations of physicians are continuously checked and practical and plans for strengthening medical cooperation are in place. In addition, it is necessary to establish an effective medical delivery system as medical referrals and returns are smoothly done between medical institutions.
\end{abstract}

Keywords: Referral, Satisfaction, Physicians, Expectations

\section{Introduction}

With the rapid increase of national medical expenses due to the aging of the population and the increase of the number of chronic diseases, questions have been raised about the sustainability of the health care system including Korea's health insurance system, and the need to establish an efficient and rational medical delivery system is increasing more than ever. The medical delivery system in Korea was introduced in 1989 with the expansion of national medical insurance. This was to ensure continuity of treatment and equity in medical care and to expect reduction of national medical expenses ${ }^{1}$.

\section{Corresponding author:}

Kwang Ok Lee

Associate Professor, Department of Nursing,

Sangmyung University, South Korea

E-mail:kolee@smu.ac.kr
As the government implemented the national health insurance, the medical delivery system at that time set eight major medical treatment zones and 142 intermediate medical treatment zones according to administrative districts and living areas, and medical institutions were classified as primary, secondary, and tertiary medical institutions. Sharing the function of the liver has also been tried ${ }^{2}$. However, as the concept of medical rights was abolished in 1998 as a regulatory reform aimed at resolving the inequality caused by the imbalance in the supply of medical resources between regions, the policy of the medical delivery system was evaluated to have failed. In the medical delivery system, the function between medical institutions has not been established, and the improvement of the income level of the people has accelerated the preference for higher quality and advanced medical services. There is a vicious cycle leading to investment and inefficiency of the treatment system. Changing to a form of care focused on 
prevention, management, and health promotion through reinforcement of primary medical services is needed. As a part of joint response to these environmental changes, a medical cooperation center was created centering to a senior hospital. As a voluntary medical delivery system, the institutional support was provided so that practitioners could easily refer patients. Therefore, the increase in patient referrals through the treatment cooperation center is receiving positive evaluation that hospital profits are increased by securing hospital medical demands and the satisfaction of practitioners is improved through referrals ${ }^{3}$. The important role of the treatment cooperation center is to identify the expectation of the practitioner in the process of referral and to provide customized services according to it to strengthen the cooperation system and to ensure that the requested patient can ultimately secure patients stably from the hospital standpoint. The Ministry of Health and Welfare and the Health Insurance Review and Assessment Service conducted a pilot project including requesting and returning treatment from May 2016 to 13 senior hospitals nationwide with a medical cooperation system, which expanded to general hospitals with more than 300 beds from May 2018. This project aimed to establish an institutionalized foundation by evaluating the validity and expansion applicability of the health insurance fee model and to induce faithful treatment through cooperation and alleviate the focus of patients to large hospitals by supporting the cost of referral and referral process. It is for the sake of five. Additionally, smooth referrals and referrals through a cooperative system between hospitals and clinics not only increase patient satisfaction and hospital profits but can also serve as an opportunity to establish a correct medical delivery system $^{6}$.

Therefore, this study was performed in a highlevel general hospital in Seoul due to the geographic location of K-city, G-city and considers the regional characteristics of the cluster of general hospitals. By investigating the expectations and satisfaction levels of the medical institutions in the local community, it is intended to seek ways to maintain and develop a close cooperation system between medical institutions in the local community and promote the vitalization of the treatment cooperation center.

\section{Methods}

Design and Subject: This study is a descriptive research study to understand the expectation demand and satisfaction of practitioners for the services of the treatment cooperation center and to compare the differences between them.

This study included a doctor who has experience requesting treatment to K-city the hospital from May to December 2019 and a doctor of a hospital or clinic who has not signed a medical treatment agreement with 80 doctors of a hospital or clinic who has signed a medical treatment agreement. Out of 160, 80 were extracted. This study was approved by the Institutional Bioethics Committee of a hospital located in K-city(IRB approval number 2019-09-004).

Measurements: In order to investigate the use of medical referrals, a questionnaire developed by Hong $^{7}$ and revised by $\mathrm{Jung}^{8}$ was used to survey the perception of practitioners' use of treatment referral centers. The contents of the questionnaire consisted of a total of 36 questions with the general characteristics of the opening of the study subject, the media used for the treatment request, the pilot project for treatment request and return, the important factors when signing the treatment cooperation, the role expectation of the treatment cooperation center, and the satisfaction after the treatment request.

In order to increase the reliability and validity of the investigation, a preliminary investigation was conducted on five hospital doctors and then revised and supplemented. This tool is composed of a fivepoint scale, and the higher the score, the higher the expectation, and satisfaction of the role of the treatment cooperation center.

From January 25, 2020, to April 25, 2020, the study participants have been subjected to convenience sampling and data collection a pre-cooperation letter 
and a questionnaire were sent to each hospital or clinic, and a questionnaire was sent to the relevant doctor by phone. The purpose of this study was explained to the participants, before they were asked to cooperate. The questionnaire was collected by personal visit or by mail or fax. Of the 129 copies (80.6\%) collected, 124 (77.5\%) were used for the final analysis, excluding five copies $(2.5 \%)$ of the questionnaire whose responses were unsatisfactory.

Data Analysis: All statistical data are expressed as mean and standard deviation. The statistical data of the target group were analyzed using the SAS statistical program (version 9.4, NC USA), and a $\mathrm{p}$ value of less than 0.05 was considered to be significant. Chi-square test was used to compare discontinuity values, and t-test or ANOVA test was used to compare each group. Linear regression analysis was used for multivariate analysis of factors affecting satisfaction.

\section{Results}

General Characteristics: In the case of partner hospitals, $67.9 \%$ were males, $47.4 \%$ were $40-49$ years old, and $57.7 \%$ were internal medicine cases. In the case of noncooperating hospitals, $82.6 \%$ were males, $50.0 \%$ were 50 59 years old, and $51.2 \%$ were surgical cases. The number of referrals for medical treatment was $64.1 \%$ within ten cases for partner hospitals and $69.6 \%$ for non-cooperating hospitals, with no significant difference between the partner hospitals and non-cooperating hospitals (Table 1).

Table 1. Comparison of characteristics between cooperation and non-cooperating groups $(N=124)$

\begin{tabular}{|c|c|c|c|c|c|c|}
\hline Variables & Categories & Total $(n=124)$ & $\begin{array}{l}\text { Cooperating } \\
\operatorname{group}(n=78)\end{array}$ & $\begin{array}{l}\text { Non-cooperating } \\
\operatorname{group}(n=46)\end{array}$ & $\begin{array}{c}\chi^{2} \\
\text { or } \mathrm{t}\end{array}$ & $\mathbf{p}$ \\
\hline Variables & Categories & $\mathrm{M} \pm \mathrm{SD}$ or $\mathrm{n}(\%)$ & $\mathrm{M} \pm \mathrm{SD}$ or $\mathrm{n}(\%)$ & $\mathrm{M} \pm \mathrm{SD}$ or $\mathrm{n}(\%)$ & $\begin{array}{c}\chi^{2} \\
\text { or } \mathrm{t}\end{array}$ & $\mathbf{p}$ \\
\hline \multirow[t]{2}{*}{ Gender } & Male & $91(73.4)$ & $53(67.9)$ & $38(82.6)$ & 2.84 & .091 \\
\hline & Femle & $33(26.6)$ & $25(32.1)$ & $8(17.4)$ & & \\
\hline \multirow[t]{4}{*}{ Age } & $<40$ & $14(11.3)$ & $12(15.4)$ & $2(4.4)$ & 9.64 & .022 \\
\hline & $40-49$ & $52(41.9)$ & $37(47.4)$ & $15(32.6)$ & & \\
\hline & $50-59$ & $43(34.7)$ & $20(25.6)$ & $23(50.0)$ & & \\
\hline & $\geq 60$ & $15(12.1)$ & $9(11.5)$ & $6(13.0)$ & & \\
\hline \multirow[t]{2}{*}{ Depart. } & Medical & $62(54.4)$ & $41(57.7)$ & $21(48.8)$ & 0.86 & .354 \\
\hline & Surgical & $52(45.6)$ & $30(42.3)$ & $22(51.2)$ & & \\
\hline \multirow[t]{4}{*}{ Regions } & K-city & $62(50.0)$ & $41(52.6)$ & $21(45.7)$ & 2.83 & .528 \\
\hline & P-city & $39(31.5)$ & $21(26.9)$ & $18(39.1)$ & & \\
\hline & G-city & $18(14.5)$ & $12(15.4)$ & $6(13.0)$ & & \\
\hline & S-city & $5(4.0)$ & $4(5.1)$ & $1(2.2)$ & & \\
\hline \multirow{2}{*}{ Case of referral } & $\leq 10$ & $82(66.1)$ & $50(64.1)$ & $29(69.6)$ & 6.08 & .193 \\
\hline & $>11$ & $42(33.9)$ & $28(35.9)$ & $14(30.4)$ & & \\
\hline Satisfaction & & $3.51 \pm 0.92$ & $3.56 \pm 0.83$ & $3.41 \pm 0.98$ & 0.89 & 0.37 \\
\hline
\end{tabular}


Media to be used when requesting medical treatment: In the case of partner hospitals, $34.9 \%$ of reservations were made to the medical cooperation center through staff, and $67.4 \%$ of non-cooperating hospitals made reservations directly by the patient through the request form. A significant difference in the media used between the two groups was found $(\chi 2=24.11, \mathrm{p}<.001)$ (Table 2).

Table 2. Characteristics of the physicians' referral between two groups $(N=124)$

\begin{tabular}{|c|c|c|c|c|c|}
\hline \multirow{2}{*}{ Variables } & $\begin{array}{c}\text { Total } \\
(n=124)\end{array}$ & $\begin{array}{l}\text { Cooperating } \\
\text { group }(n=78)\end{array}$ & $\begin{array}{l}\text { Non-cooperating } \\
\text { group }(n=46)\end{array}$ & \multirow{2}{*}{$\chi^{2}$} & \multirow{2}{*}{ p } \\
\hline & $\mathbf{n}(\%)$ & $\mathbf{n}(\%)$ & $\mathbf{n}(\%)$ & & \\
\hline Register for the request portal & $5(6.0)$ & $5(6.0)$ & $0(0.0)$ & 24.11 & $<.001$ \\
\hline Direct application of physician's & $27(20.9)$ & $19(22.9)$ & $8(17.4)$ & & \\
\hline Application through medical staff & $6(4.7)$ & $6(7.2)$ & $0(0.0)$ & & \\
\hline Application through staff & $33(25.6)$ & $28(33.7)$ & $5(10.9)$ & & \\
\hline Referral application form(by person) & $55(42.6)$ & 24(28.9) & $31(67.4)$ & & \\
\hline Etc. & $3(2.3)$ & $1(1.2)$ & $2(4.4)$ & & \\
\hline
\end{tabular}

Important factors when signing a medical treatment cooperation institution: As for the important factors when signing a treatment cooperation institution, partner hospitals were included based on the following: order of promptness of treatment request, treatment request/ return system, medical care level, patient preference, possession of advanced medical equipment, convenience of use of subsidiary facilities, and promotion of signing of cooperation hospitals. Cooperating hospitals were in the order of referral/return system, expedited treatment request, medical staff treatment level, patient preference, advanced medical equipment, convenience of use of auxiliary facilities, and promotion of cooperation with hospitals. It was analyzed that the items of possession of advanced medical equipment $(t=2.11, p<0.36)$ and the level of care by medical staff $(t=2.05, p<0.43)$ were significant (Table $3)$. 
Table 3. Important factors for signing a cooperating hospital between two groups $(N=\mathbf{1 2 4})$

\begin{tabular}{|c|c|c|c|c|c|}
\hline \multirow{2}{*}{ Variables } & Total $(n=124)$ & $\begin{array}{l}\text { Cooperating } \\
\operatorname{group}(n=78)\end{array}$ & $\begin{array}{l}\text { Non-cooperating } \\
\operatorname{group}(n=46)\end{array}$ & \multirow{2}{*}{$\mathbf{t}$} & \multirow{2}{*}{$\mathbf{p}$} \\
\hline & $\mathbf{M} \pm \mathbf{S D}$ & $\mathbf{M} \pm \mathbf{S D}$ & $\mathbf{M} \pm \mathbf{S D}$ & & \\
\hline Possess advanced medical equipment & $3.92 \pm 0.74$ & $4.03 \pm 0.66$ & $3.74 \pm 0.83$ & 2.11 & .036 \\
\hline Medical referral-returning system & $4.37 \pm 0.75$ & $4.42 \pm 0.67$ & $4.28 \pm 0.86$ & 1.01 & .314 \\
\hline Expedited medical referral & $4.39 \pm 0.73$ & $4.45 \pm 0.66$ & $4.28 \pm 0.83$ & 1.26 & .208 \\
\hline Medical staff level of care & $4.31 \pm 0.68$ & $4.41 \pm 0.59$ & $4.13 \pm 0.79$ & 2.05 & .043 \\
\hline Patient preferences & $4.07 \pm 0.75$ & $4.13 \pm 0.67$ & $3.98 \pm 0.87$ & 1.07 & .284 \\
\hline $\begin{array}{l}\text { Promotion through cooperating } \\
\text { hospitals }\end{array}$ & $3.25 \pm 0.98$ & $3.37 \pm 0.93$ & $3.04 \pm 1.03$ & 1.83 & .070 \\
\hline Convenience of using auxiliary facilities & $3.40 \pm 1.09$ & $3.49 \pm 1.08$ & $3.26 \pm 1.10$ & 1.12 & .265 \\
\hline
\end{tabular}

Comparison of trial project of referral/return: Participation in the trial referral/return pilot project was $45.5 \%$ and $4.4 \%$ for partner hospitals and non-cooperating hospitals, respectively, while the participation in the pilot project was 91.4\% and 54.5\% for partner hospitals and non-cooperating institutions, respectively. In the case of activation of the pilot project, $70.7 \%$ and $47.7 \%$ of partner hospitals and non-cooperation hospitals, respectively, show that the opinions between the two groups are different (Table 4).

Table 4. Comparison of pilot project of referral-returning for medical treatment between two groups $(N=124)$

\begin{tabular}{|c|c|c|c|c|c|c|}
\hline \multirow{2}{*}{ Variables } & \multirow{2}{*}{ Categories } & $\begin{array}{c}\text { Total } \\
(n=124)\end{array}$ & $\begin{array}{l}\text { Cooperating } \\
\operatorname{group}(n=78)\end{array}$ & $\begin{array}{l}\text { Non-cooperating } \\
\text { group }(n=46)\end{array}$ & \multirow{2}{*}{$x^{2}$} & \multirow{2}{*}{$p$} \\
\hline & & n(\%) & $\mathrm{n}(\%)$ & $\mathrm{n}(\%)$ & & \\
\hline \multirow{2}{*}{ Participation } & Yes & $37(30.3)$ & $35(45.5)$ & $2(4.4)$ & 22.61 & $<.001$ \\
\hline & No & $85(69.7)$ & $42(54.5)$ & $43(95.6)$ & & \\
\hline \multirow[t]{2}{*}{$\begin{array}{l}\text { Apply for medical } \\
\text { fee }\end{array}$} & Yes & $85(70.3)$ & $32(91.4)$ & $24(54.5)$ & 8.16 & .004 \\
\hline & No & $36(29.7)$ & $3(8.6)$ & $20(45.5)$ & & \\
\hline \multirow[t]{2}{*}{ Activation } & Yes & $74(62.2)$ & $53(70.7)$ & $21(47.7)$ & 6.21 & .012 \\
\hline & No & $45(37.8)$ & $22(29.3)$ & $23(52.3)$ & & \\
\hline
\end{tabular}




\section{Conclusion}

The Treatment Cooperation Center is one of the central departments that enable the medical delivery system to work naturally according to environmental changes, as a place that performs functions and roles including quick appointment of treatment, treatment, response of treatment results, and return after treatment of patients requesting treatment at partner hospitals. It can be seen that in order to make the medical delivery system more efficient, the role of the treatment cooperation center, which serves as a bridge in connection between hospitals, should be strengthened primarily.

If the pilot project for referral and return for medical treatment is activated, the Medical Cooperation Center will establish a close cooperation system with hospitals and clinics, contributing to the development of local community medical care and improvement of residents' health. In order to facilitate the outpatient return of hospital-level medical institutions, the return rate has been reviewed, and the patient-centered medical system based on the local community has been established by providing the optimal medical service through prompt treatment and return after treatment for the requested patient. It is expected to contribute to establishing a correct medical delivery system.

\section{Conflict of Interest : Nil}

\section{Ethical Clearance: None}

Source of Funding : National Health Insurance Service Ilsan Hospital

\section{References}

1. Cho JG. An Improvement Plan for Health Care Delivery System. Health and Welfare Forum. 2012;169:6-15.

2. Yoon GJ, Oh YH, Lee SH, Ha SL, Kim JH, Yeo JY, et al. Issues and Improving Strategies on Korea Healthcare Delivery System. Sejong: Korea Institute for Health and Social Affairs. 2014.

3. Song HJ. A study on the nursing service performances at a medical referral center: Ewha Womans University. 2004.

4. Han SH. Survey of Doctors` Role Expectation and Patients Satisfaction with Referral Centers. Journal of Korean Academy of Nursing Administration. 2007; 13(1):74-81.

5. Ministry of Health and Welfare. Guidelines for pilot projects of referral/return between cooperative agencies. 2020.

6. Youn KI. An Analysis of the Relationship among the Hospital Standardization Survey Score, Efficiency, and Profitability in Acute Care Hospitals. Health Policy and Management. 2001;11(4):38-53.

7. Hong SS. A study on the physicians' perception of patient referral centers in tertiary hospitals: Hanyang University. 1999.

8. Kim OH. Expectation Need and Satisfaction of Private Practitioners Using the Referral Center of an University Hospitals: Chungnam National University. 2008.

9. Cha SW, Lee MS, Ko BM, Kim JO, Jo JY, Sim CS. Management and evaluation of referral patient medical referral. Journal of Korean Society of Quality Assurance in Health Care. 2000;385-91.

10. Min HY, Lee JC. An improvement plan for patient referral system. Korean Medical Association. 2010;1-155. 